\title{
Pengembangan Aplikasi Katalog Perpustakaan Terintegrasi Menggunakan Metode RESTful pada Perpustakaan Kota Semarang dan Perpustakaan Daerah Jawa Tengah
}

\author{
Egia Rosi Subhiyakto ${ }^{1 *}$, Yani Parti Astuti ${ }^{2}$, Novita Kurnia Ningrum ${ }^{3}$ \\ 1,2,3 Jurusan Teknik Informatika, Fakultas Ilmu Komputer, Universitas Dian Nuswantoro, Semarang \\ 1,2,3 Jln. Imam Bonjol No 207, Kota Semarang, 50131, Indonesia \\ email: ${ }^{1}$ egia@dsn.dinus.ac.id, ${ }^{2}$ yanipartiastuti@dsn.dinus.ac.id, ${ }^{3}$ novita.kn@dsn.dinus.ac.id
}

Received: 19 Maret 2018; Revised: 7 Mei 2018; Accepted: 13 Mei 2018

Copyright $\odot 2018$ Politeknik Harapan Bersama Tegal. All rights reserved

\begin{abstract}
Development of technology allows access to information becomes an easy thing to do. Along the way, the majority of agencies, both private and government, have an adequate source of information in the form of website applications. The use of website applications is growing in terms of access to information. It is not unusual that access to the current library catalog more uses an information system. The problem arises when the number of library catalogs that can be accessed but still separate, in the sense of having to move from one website to another website to access the catalog. The existence of web service technology is a solution to connect access one website application with another website. In this research, the library catalog access is integrated. The library is a case study of the library of Semarang City and Central Java Regional Library. The method used in this research is a light RESTful method in resource consumption so that it can be more efficient. The catalog integration application has been successfully built using the PHP programming language and MySQL database. Evaluation results show the application has been built, have a satisfactory performance, easy to use, useful and the majority of users are satisfied to use the application.
\end{abstract}

Abstrak - Perkembangan teknologi dewasa ini memungkinkan akses informasi menjadi hal yang mudah untuk dilakukan. Seiring hal tersebut mayoritas instansi baik swasta maupun pemerintah memiliki sumber informasi yang memadai dalam bentuk aplikasi website. Penggunaan aplikasi website semakin berkembang dalam hal akses informasi. Sudah tidak aneh lagi bahwa akses katalog perpustakaan saat ini lebih banyak yang menggunakan sebuah sistem informasi. Permasalahan muncul ketika banyaknya katalog perpustakaan yang dapat diakses tetapi masih terpisah, dalam artian harus berpindah dari satu website ke website yang lain untuk mengakses katalog. Adanya teknologi web service merupakan solusi untuk menghubungkan akses satu aplikasi website dengan website lainnya. Dalam penelitian ini dilakukan pengintegrasian akses katalog buku perpustakaan. Perpustakaan yang menjadi studi kasus yakni perpustakaan Kota Semarang dan perpustakaan Daerah Jawa Tengah. Metode yang digunakan dalam penelitian ini adalah metode RESTful yang ringan dalam konsumsi sumber daya

*) Corresponding author: Egia Rosi Subhiyakto

Email: egia@dsn.dinus.ac.id sehingga dapat elebih efisien. Aplikasi integrasI katalog telah berhasil dibangun menggunakan bahasa pemrograman PHP dan basisdata MySQL. Hasil evaluasi menunjukan bahwa aplikasi yang dibnagun memiliki kinerja yang memuaskan, mudah digunakan, bermanfaat dan mayoritas pengguna puas menggunakan aplikasi tersebut.

Kata Kunci - Integrasi, Katalog, Perpustakaan, RESTful, JSON.

\section{PENDAHULUAN}

Internet tidak dipungkiri lagi dapat dijadikan sebagai sumber utama akses informasi saat ini. Segala jenis informasi dapat didapatkan, mulai dari berita online, akses video, akses audio, dan segala informasi yang terbaru dan ter-update. Salah satu media yang biasa digunakan dalam mengakses internet adalah aplikasi web. Aplikasi web merupakan program aplikasi yang disimpan dan di kirim melalui internet dengan menggunakan antarmuka browser [1]. Penggunaan aplikasi website dewasa ini hampir semua instansi baik pemerintah maupun swasta memilikinya. Tak terkecuali website katalog perpustakaan yang ada di sebuah instansi. Banyaknya website yang memuat katalog perpustakaan instansi menimbulkan permasalahan yang relatif kompleks. Kesulitan untuk mencari website yang valid juga menjadi hal yang lumayan sulit bagi orang awam atau pemula dalam mengakses website tersebut. Kemudahan akses bagi pengguna tanpa harus berpindah website merupakan solusi alternatif yang dapat digunakan.

Dukungan teknologi web service juga dapat menjadi solusi permasalahan tersebut. Teknologi ini mempunyai sifat yang netral, sustainable, rancangan platformnya independen, handal, kemampuan interoperabilitas yang tinggi dan juga interdependency yang rendah [2]. Teknologi ini berbasiskan kepada sebuah konsep yakni konsep layanan beroerientasi kepada arsitektur atau sering dikenal dengan istilah SOA (Service Oriented Architecture) [3]. Penggunaan teknologi web service juga dapat digunakan dalam rangka menghubungkan aplikasi satu dengan aplikasi lainnya dengan sebuah basisdata walaupun berbeda bahasa pemrograman dan 
tidak memerlukan driver dari basisdata untuk mengakses basisdata tersebut[4].

Dalam prakteknya teknologi web service terdidri dari dua metode yakni SOAP (Simple Object Access Protocol) dan REST (Representational State Transfer Protocol) [2][5]. Penggunaan SOA berorientasi pada layanan dalam mengembangkan aplikasinya dan lebih aman, serta cocok untuk kebutuhan keamanan tinggi, sedangkan REST memiliki orientasi pada sumber daya sehingga pengembangan aplikasi dengan metode ini lebih cepat dan mengkonsumsi sumber daya lebih sedikit [3].

Penelitian ini akan berfokus pada pengembangan aplikasi dalam rangka integrasi katalog perpustakaan khususnya perpustakaan umum Kota Semarang dan perpustakaan Daerah Jawa Tengah. Pemilihan penggunaan metode REST dalam implementasinya dikarenakan metode ini lebih cepat dan efisien dibandingkan SOAP dikarenakan konsumsi sumber daya lebih sedikit [3][5], sehingga cocok untuk diimplementasikan dalam kasus penelitian yang dibahas. Sistem yang dibangun akan menampilkan katalog-katalog perpustakaan hanya dalam satu aplikasi sehingga diharapkan lebih efisien bagi pengguna dalam pencarian katalog perpustakaan terkait.

\section{PENELITIAN YANG TERKAIT}

Penelitian terkait yang sebelumnya dilakukan berkaitan dengan penggunaan metode REST dibahas dalam [3] yang memaparkan perbandingan metode SOAP dan REST untuk mobile host. Penelitian tersebut menyajikan perbandingan rinci antara dua kerangka kerja yang digunakan untuk menyediakan layanan web melalui SOAP dan REST dan juga membahas masalah dan tantangan dalam kedua kerangka kerja ini. Dengan bantuan perbandingan, dapat ditenentukan kerangka kerja mana yang paling sesuai untuk lingkungan nirkabel dan memenuhi kebutuhan saat mengakses layanan web seluler ringan secara terus menerus dari perangkat seluler yang dibatasi sumber daya.

Penelitian lain yang membahas penggunaan metode RESTful dalam [6] dilakukan perbandingan metode SOAP dan REST di simulator pertanian yang didukung oleh Layanan Web yang diakses dari smartphone Android. Hasilnya penggunaan memori $24 \%$ lebih rendah di SOAP, namun smartphone yang lebih tua dan yang lebih rendah memiliki RAM yang cukup untuk menghindari efek yang merugikan pada kinerja. Pendekatan berbasis REST secara luas mengalami transfer byte yang kurang dibandingkan SOAP, yang memiliki implikasi besar pada biaya. Itu sangat penting saat Internet diakses melalui protokol GPRS atau 3G dan paket data bayar per-byte seperti di sebagian besar wilayah pedesaan.

Penggunaan metode RESTful dalam flatform android terdapat pada penelitian [7] yang melakukan eksplorasi gagasan tentang layanan mashup yang mengintegrasikan layanan web individual yang dapat memenuhi persyaratan pengguna akhir. Dalam penelitian ini diusulkan sebuah algoritma rekursif. Implementasinya ada di Android 2.2 (froyo), level API 8 keatas. Hal ini didukung pada sebagian besar perangkat mobile berbasis Android. Metode RESTful juga digunakan dalam penelitian [8] yang mengusulkan sebuah arsitektur dengan menggunakan data sensor sebagai layanan melalui web. Arsitektur ini juga mempertimbangkan lokasi pengguna untuk menyediakan data cuaca dari sensor terdekat yang ada. Penelitian ini juga memberikan analisis rinci dan perbandingan antara RESTful dan layanan web berbasis WSDL / SOAP.

\section{METODE PENELITIAN}

Metode yang digunakan dalam penelitian ini adalah metode RESTful web service. Untuk output datanya menggunakan format data JSON. Pemilihan metode REST didasarkan pada penelitian terkait yang sudah dipaparkan sebelumnya yakni kecepatan akses dan performa karena konsumsi sumber daya yang sedikit. Sedangkan format JSON dipilih karena lebih ringan jika dibandingkan dengan XML. Gbr 1 menunjukan alur system yang akan dibangun. Terdapat input berupa data dari server baik dari perpustakaan Kota maupun perpustakaan Daerah. Kemudian Application Programming Interface (API) digunakan untuk dapat mengakses data dari server asal dan mengubahnya ke dalam format data JSON, lalu data ditampilkan ke dalam aplikasi web. Data diambil dengan pengaksesan URL oleh aplikasi web yang berfungsi sebagai service requester dan API yang berfungsi sebagai agent yang akan melakukan query terhadap server sebagai service provider.

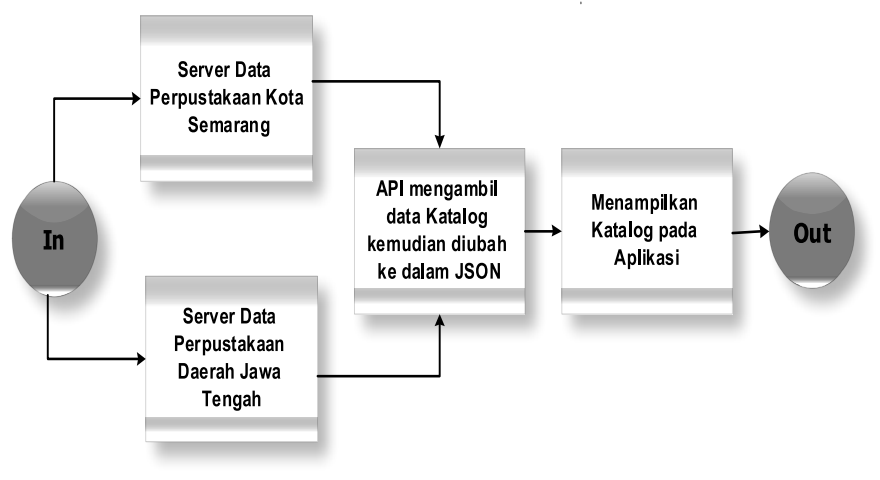

Gbr. 1 Alur sistem

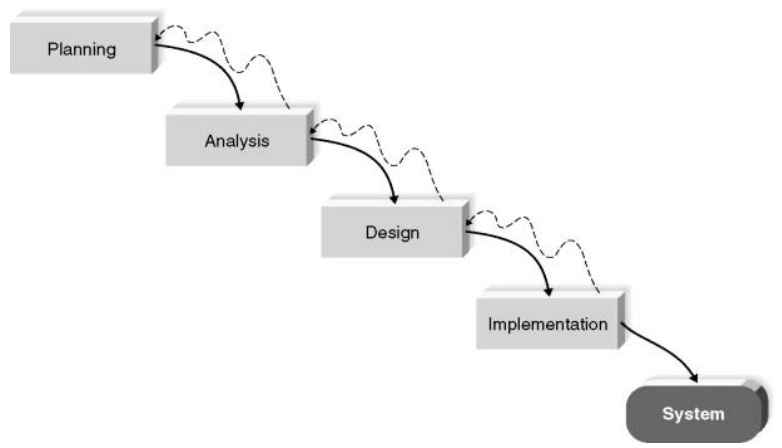

Gbr. 2 Metode waterfall [15]

Sedangkan untuk metode pengembangan sistem yang digunakan dalam penelitian ini adalah metode waterfall. Pemilihan metode ini didasarkan bahwa setiap tahap menghasilkan hasil yang matang dimulai dari fase perencanaan, analisis, perancangan, implementasi dalam bentuk koding sampai menjadi sebuah sistem. Penelitian lain yang menggunakan metode waterfall terdapat pada penelitian [9][10][11][12]. Untuk menjadi seorang software developer 
yang mempunyai kompetensi diharapakan dapat menguasai semua tahap pengembangan [13] dan dapat bekerjasama dalam tim [14]. Gbr 1 menunjukkan proses pengembangan sistem menggunakan metode waterfall.

\section{HASIL DAN PEMBAHASAN}

Pembuatan aplikasi web integrasi katalog dibagi menjadi tiga tahap yaitu tahap analisis kebutuhan data, tahap perancangan dan tahap implementasi sistem.

\section{A. Analisis dan Perancangan}

Objek yang dijadikan bahan penelitian adalah perpustakaan umum Kota Seamarang dan perpustakaan Daerah Jawa Tengah. Analisis dilakukan menggunakan UML (Unified Modeling Language), diagram yang digunakan yakni diagram use case dan diagram kelas. Kustomisasi alat pemodelan pernah dilakukan dalam penelitian [9][13] yang memaparkan bahwa penggunaan diagram UML adalah sebuah standar de facto dalam analisis dan perancangan berorientasi objek. Gbr 3 menunjukkan diagram use case untuk sistem integrase katalog perpustakaan. Dalam diagram tersebut terdapat satu pengguna dengan spesifikasi pengguna umum yang ingin mengakses aplikasi website katalog perpustakaan. Fungsionalitas aplikasi terdiri dari menu akses katalog perpustakaan umum Kota Semarang, menu katalog perpustakaan Daerah Jawa Tengah, tentang aplikasi, dan menu untuk menghubungi administrator sistem. Dalam mengakses katalog baik katalog perpustakaan Kota maupun Daerah terdapat detail katalog yang berisi judul buku, penulis, penerbit, tahun terbit, lokasi perpustakaan, dan nomor telepon.

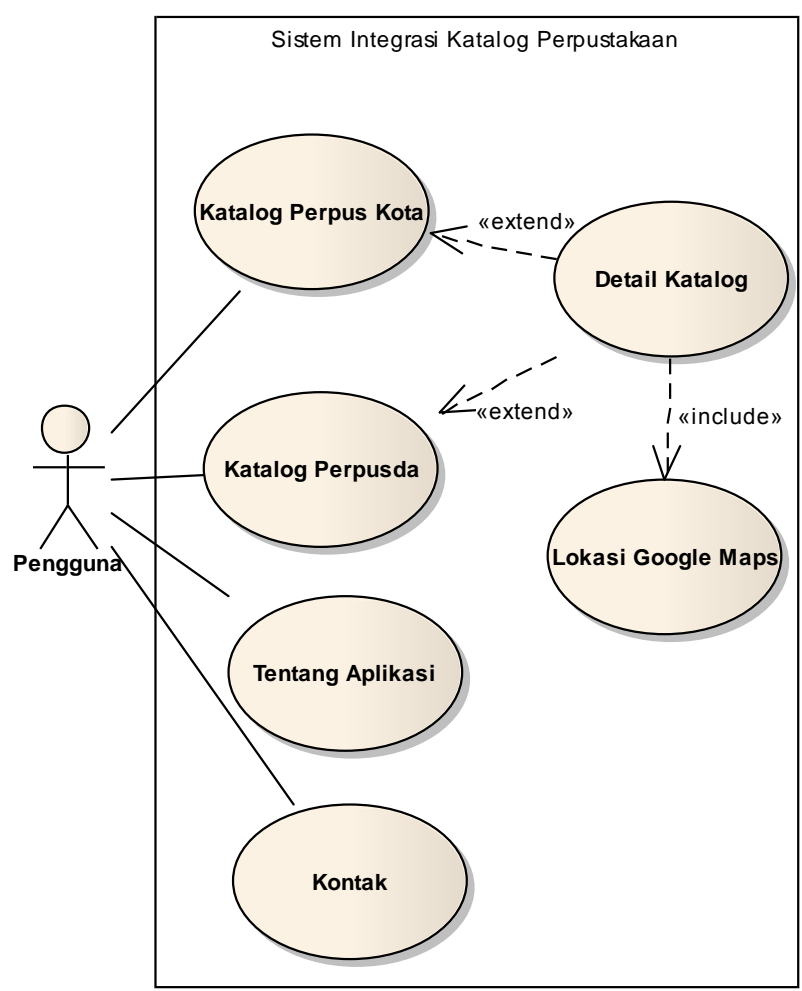

Gbr. 3 Diagram use case sistem integrasi katalog
Untuk menggambarkan hubungan statis antar objek dalam sistem digambarkan dalam diagram kelas seperti dalam gbr 4 . Dalam gbr tersebut terdapat empat kelas yakni kelas pengguna, kelas kontak, kelas katalog kota dan kelas katalog daerah. Dalam kelas-kelas tersebut memiliki atribut dan method masing-masing.

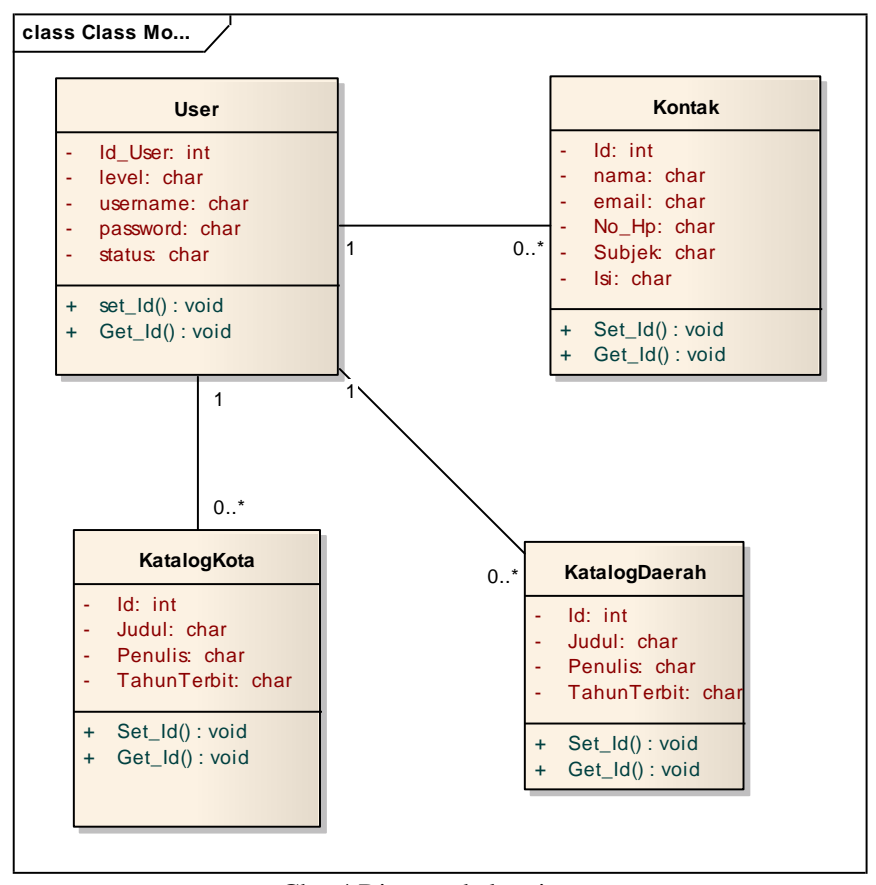

Gbr. 4 Diagram kelas sistem

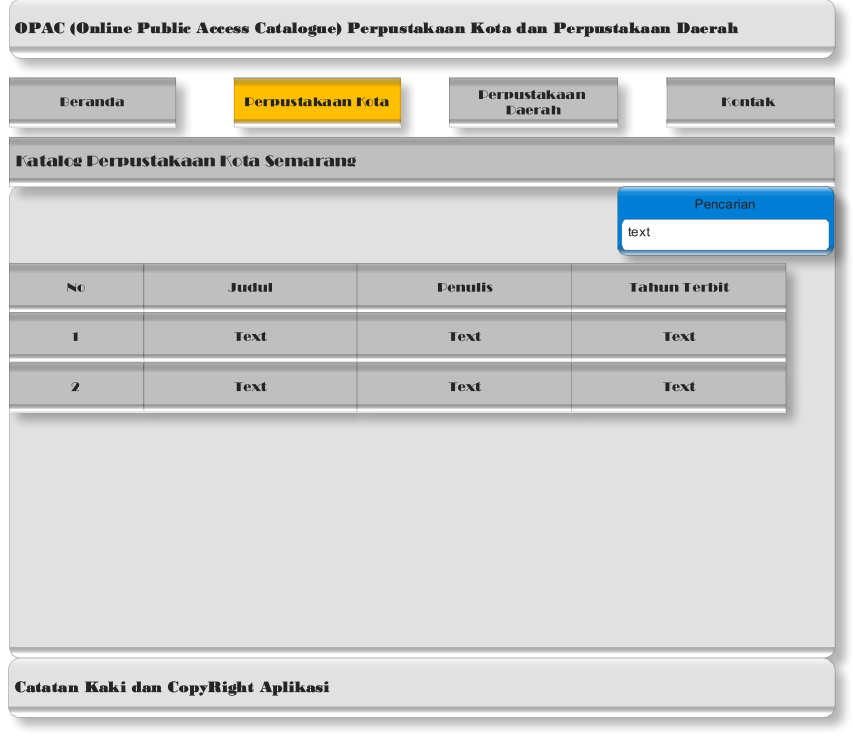

Gbr. 5 Perancangan antarmuka halaman katalog

Tahap perancangan dilakukan setelah tahapan analisis dilakukan. Dalam perancangan dilakukan perancangan arsitektur, perancangan data dan perancangan antarmuka. Gbr 5 menunjukkan salah satu contoh perancangan antarmuka halaman utama. Dalam halaman ini dirancang untuk menampilkan katalog buku di perpustakaan baik untuk perpustakaan Kota maupun perpustakaan Daerah. 


\section{B. Tahap Implementasi Sistem}

Tahapan ini merupakan tahapan yang dilakukan setelah proses analisis dan perancangan dilakukann. Pada tahap implementasi dilakukan proses pengkodean untuk system yang dibangun.

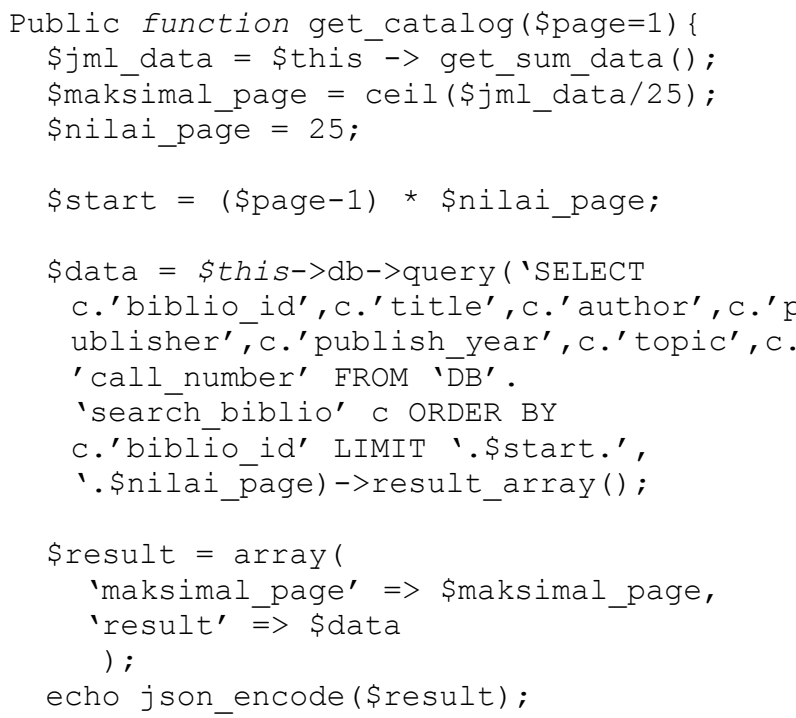

Gbr. 6 Pengambilan data dari server oleh API

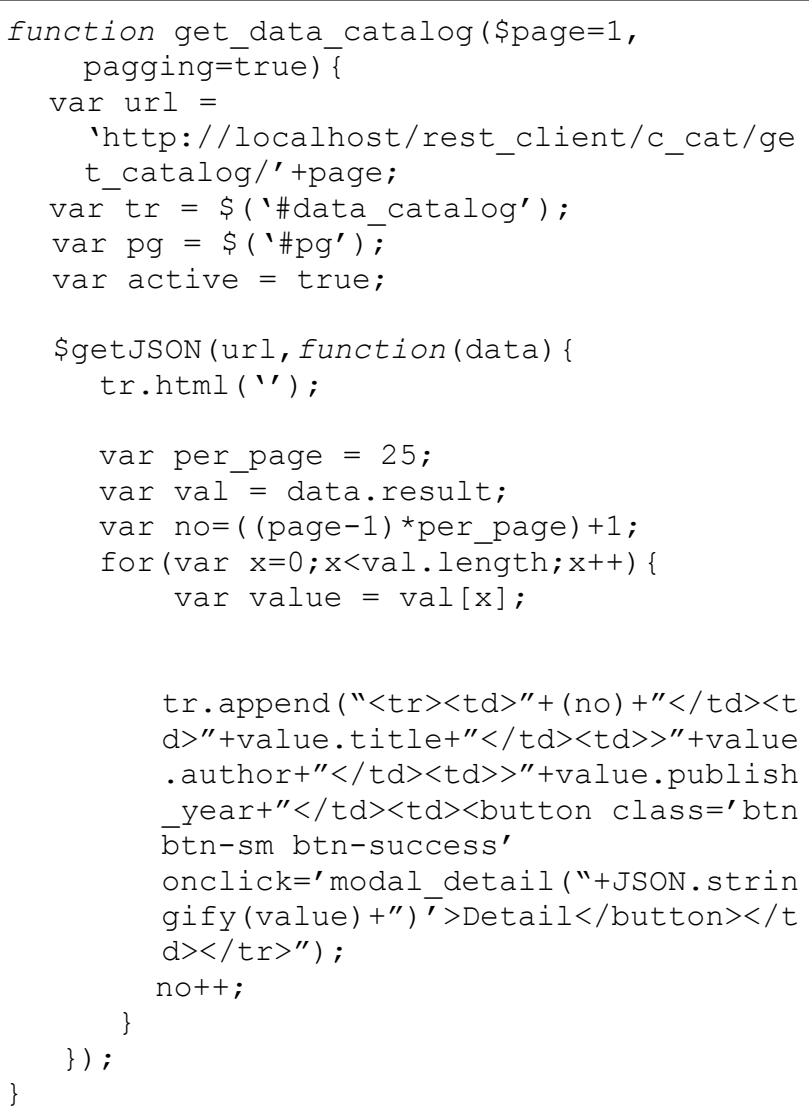

Gbr. 7 Method akses data pada API
Gbr 6 menunjukkan proses pengambilan data yang dilakukan oleh (Application Programming Interface) atau API. Proses pengambilan data katalog dilakukan per bagian agar proses berjalan dinamis. Hasil query nantinya berbentuk array yang akan ditampung dalam variabel result lalu dilakukan proses json_encode untuk mengubah data pada array menjadi format data JSON. Untuk menampilkan data pada antarmuka aplikasi web integrasi katalog menggunakan fungsi getJSON seperti yang ditunjukkan pada gbr 7. Data yang ada pada variabel result dalam API dapat diakses melalui Uniform Resource Locator (URL) sehingga dapat ditampilkan pada halaman antarmuka aplikasi.

Implementasi antarmuka dilakukan menggunakan bahasa pemrograman php dan basisdata mysql. Gbr 8 menunjukkan halaman beranda aplikasi web yang dibuat. Dalam halaman beranda terdapat penjelasan mengenai aplikasi yang dibuat, serta beberapa menu untuk mengakses katalog perpustakaan Kota dan perpustakaan daerah serta kontak untuk menyampaikan kritik dan saran.
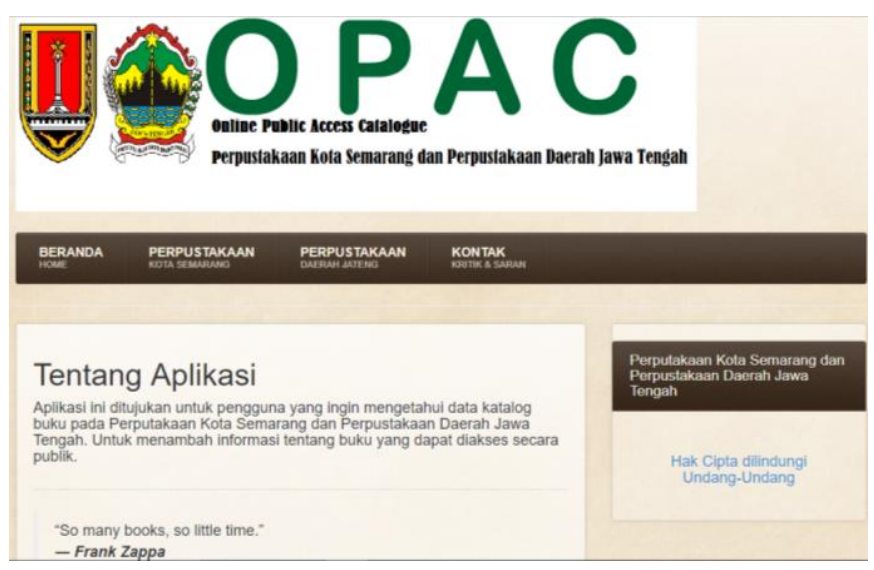

Gbr. 8 Tampilan halaman beranda

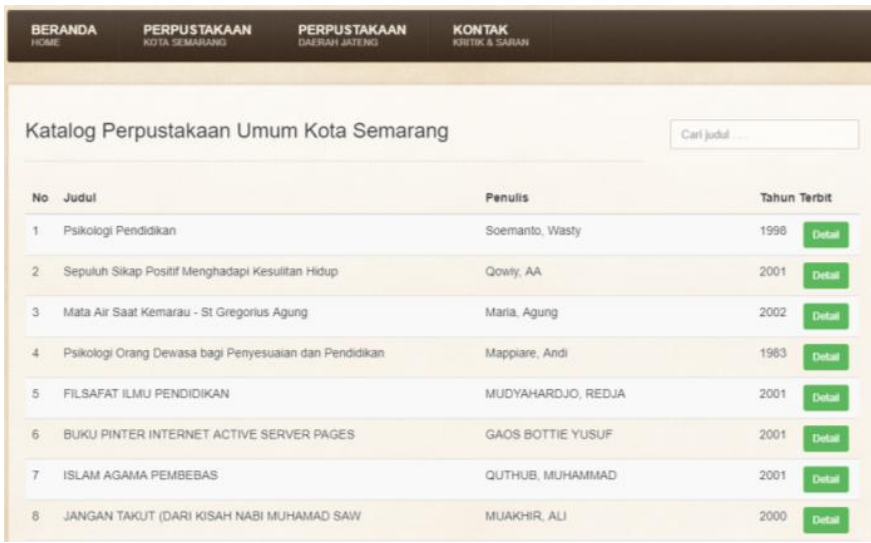

Gbr. 9 Tampilan katalog perpustakaan kota

Gbr 9 menunjukkan tampilan katalog perpustakaan Kota Semarang. Dalam antarmuka tersebut dapat dilihat katalog berdasrkan judul, penulis, tahun terbit. Juga dapat dilakukan pencarian berdasarkan judul. Menu detail katalog dapat di klik untuk melihat secara rinci katalog yang dituju. 
Sama halnya dengan katalog perpustakaan Kota, katalog perpustakaan Daerah juga menampilkan informasi judul, penulis dan tahun terbit serta informasi detail katalog. Gbr 10 menunjukan daftar katalog yang ada di perpustakaan Daerah Jawa Tengah.

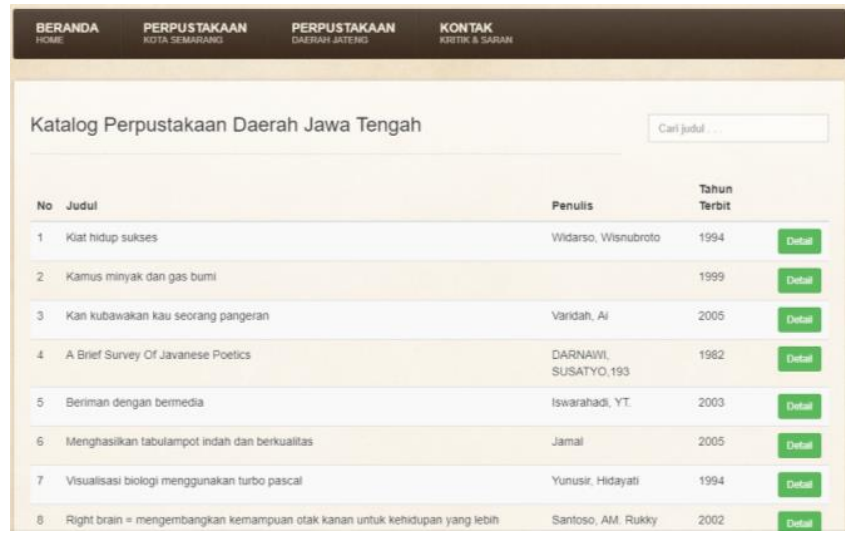

Gbr. 10 Tampilan katalog perpustakaan daerah

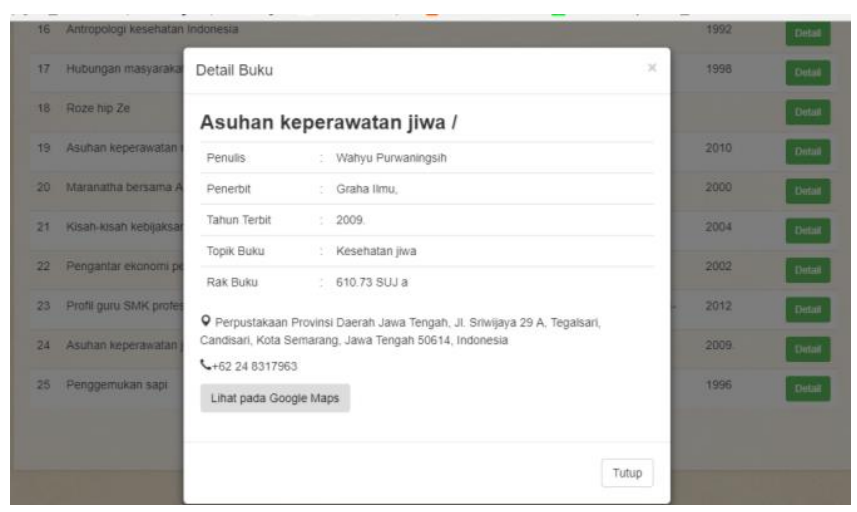

Gbr. 11 Detail katalog buku

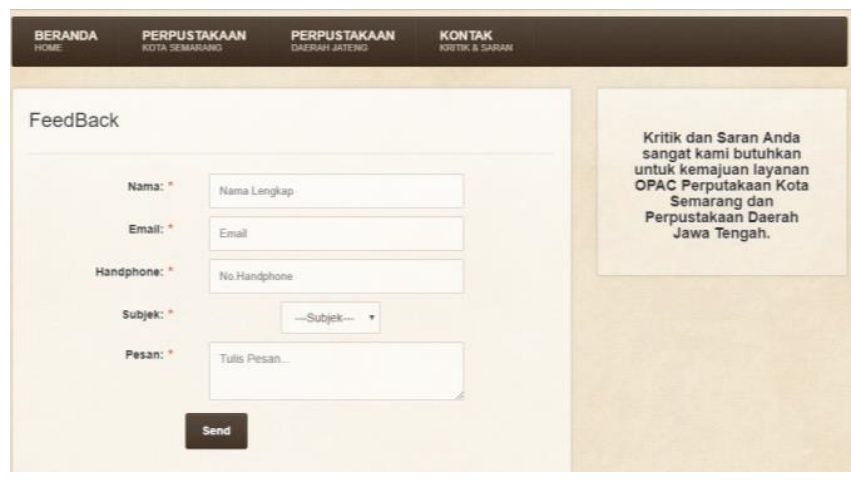

Gbr. 12 Halaman kontak

Detail katalog buku dapat dilihat pada gbr 11. Dalam detail ini ditunjukkan judul buku, penulis, penerbit, tahun terbit buku, topik buku, dan lokasi posisi buku di rak perpustakaan. Selain itu juga dalam detail terdapat alamat lengkap, nomor telepon dan lokasi perpustakaan dalam google maps. Gbr 11 menunjukan form kontak yang bertujuan mengirimkan umpan balik. Form kontak terdiri dari masukan nama, email, nomor handphone, subjek judul dan pesan yang akan disampaikan. Hasil dari masukan kontak akan disampaikan ke administrator aplikasi integrasi katalog.

\section{Tahap Pengujian Sistem}

Pengujian sistem dilakukan dengan menggunakan metode black box yang menguji dari sisi fungsionalitas sistem. Pemilihan metode pengujian berdasarkan [16][17]. Dalam makalah tersebut memuat beberapa metode pengujian sistem baik menggunakan black box maupun white box.

TABEL I

PENGUJIAN BLACKBOX PENCARIAN KATALOG

\begin{tabular}{|l|l|}
\hline \multicolumn{2}{|c|}{ Kasus Data dan Hasil Uji (Data Benar) } \\
\hline Data Masukan & $\begin{array}{l}\text { Pencarian katalog buku (data diisi } \\
\text { dengan benar) }\end{array}$ \\
\hline Yang diharapkan & $\begin{array}{l}\text { Aplikasi menampilkan hasil } \\
\text { pencarian yang benar }\end{array}$ \\
\hline Pengamatan & $\begin{array}{l}\text { Hasil pencarian sesuai dengan } \\
\text { masukan }\end{array}$ \\
\hline Kesimpulan & Pengujian Diterima \\
\hline \multicolumn{1}{|c|}{ Kasus Data dan Hasil Uji (Data Salah) } \\
\hline Data Masukan & Pencarian diisi data kosong \\
\hline Yang Diharapkan & $\begin{array}{l}\text { Muncul pesan bahwa masukan } \\
\text { harus diisi }\end{array}$ \\
\hline Pengamatan & Muncul pesan kesalahan \\
\hline Kesimpulan & Pengujian Diterima \\
\hline
\end{tabular}

TABEL II

PENGUJIAN BLACKBOX FORM KONTAK

\begin{tabular}{|l|l|}
\hline \multicolumn{2}{|c|}{ Kasus Data dan Hasil Uji (Data Benar) } \\
\hline Data Masukan & $\begin{array}{l}\text { Masukan field sesuai (data diisi } \\
\text { dengan benar) }\end{array}$ \\
\hline Yang diharapkan & $\begin{array}{l}\text { Aplikasi menampilkan bahwa } \\
\text { pesan telah dikirim dan sesuai }\end{array}$ \\
\hline Pengamatan & Inputan berhasil \\
\hline Kesimpulan & Pengujian Diterima \\
\hline \multicolumn{1}{|c|}{ Kasus Data dan Hasil Uji (Data Salah) } \\
\hline Data Masukan & Masukan diisi data kosong \\
\hline Yang Diharapkan & $\begin{array}{l}\text { Muncul pesan bahwa masukan } \\
\text { harus diisi }\end{array}$ \\
\hline Pengamatan & Muncul pesan kesalahan \\
\hline Kesimpulan & Pengujian Diterima \\
\hline
\end{tabular}

Selain pengujian dengan metode black box, juga dilakukan pengujian user acceptance kepada pengguna sistem. Pengujian dilakukan untuk menguji kelayakan sistem yang dibuat. Pengujian dilakukan dengan memberikan penjelasan singkat mengenai aplikasi terlebih dahulu kepada pengguna. Setelah diberikan penjelasan lalu diberikan kuisioner sebagai umpan balik. Terdapat 30 orang responden yang berpartisipasi, partisipan merupakan pengunjung perpustakaan baik perpustakaan Kota maupun perpustakaan Daerah. Pengujian ini memberikan 10 pernyataan yang berhubungan dengan system yang mencakup kinerja system, kemudahan penggunaan, dan kepuasan pengguna. Untuk 
mengukur dilakukan dengan parameter skala likert, yakni sangat setuju, setuju, tidak setuju, dan sangat tidak setuju.

Gbr. 13 menunjukan grafik hasil evaluasi terhadap responden. Grafik menunjukan respon yang positif untuk semua pernyataan yang diberikan. Untuk kinerja sistem lebih dari $93 \%$ responden sangat setuju dan setuju bahwa kinerja sistem sudah baik. Lebih dari $90 \%$ responden juga sangat setuju dan setuju bahwa sistem mudah digunakan, $87 \%$ responden menyatakan sistem bermanfaat, dan lebih dari $90 \%$ responden menyatakan puas menggunakan sistem ini. Hal ini dapat disimpulkan bahwa sistem memiliki kinerja yang baik, mudah digunakan, bermanfaat dan responden puas dengan sistem yang dibangun.

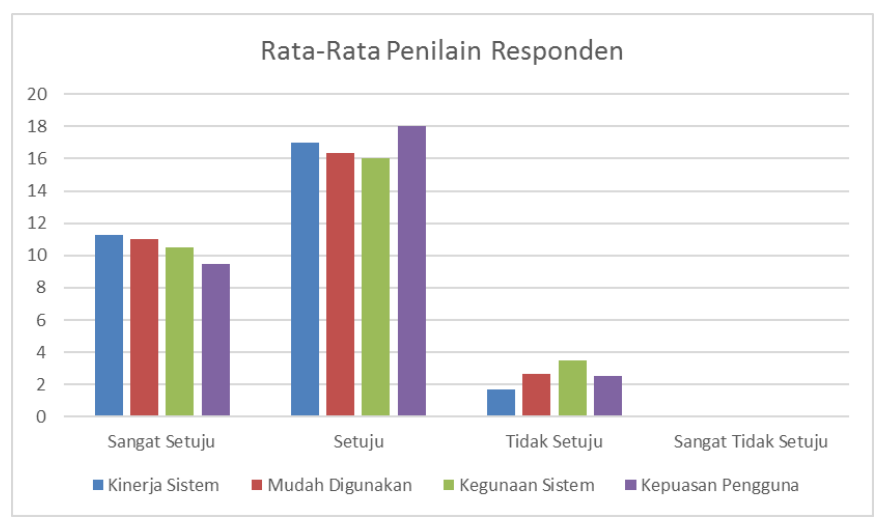

Gbr. 13 Grafik hasil evaluasi sistem

\section{KESIMPULAN}

Aplikasi katalog perpustakaan yang terintegrasi telah berhasil dibangun dan diuji menggunakan pengujian black box. Selain itu juga telah dilakukan pengujian user acceptance yang ditujukan kepada responden yang merupakan pengunjung perpustakaan baik perpustakaan Kota maupun perpustakaan Daerah. Evaluasi dilakukan dengan memberikan kuisioner sebagai umpan balik dengan menggunakan empat parameter yakni kinerja sistem, kemudahan penggunaan, kegunaan sistem dan kepuasan pengguna. Hasil evaluasi menunjukan bahwa mayoritas pengguna sangat setuju dan setuju bahwa aplikasi yang dibangun memiliki kinerja yang baik, mudah digunakan, aplikasi bermanfaat dan pengguna puas terhadap aplikasi yang dibangun. Penelitian selanjutnya adalah mengembangkan integrase katalog perpustakaan instansi lain baik swasta maupun pemerintah.

\section{UCAPAN TERIMA KASIH}

Ucapan terima kasih disampaikan kepada LPPM Universitas Dian Nuswantoro Semarang untuk pendanaan penelitian, melalui penelitian Iptek dengan nomor kontrak 016/A.38.04/UDN-09/I/2018.

\section{DAFTAR PUSTAKA}

[1] Techtarget, "Web application (Web app)," 2018. [Online]. Available: http://searchsoftwarequality.techtarget.com/definition/Webapplication-Web-app. [Accessed: 14-Mar-2018].

[2] S. Kumari and S. K. Rath, "Performance comparison of SOAP and REST based Web Services for Enterprise Application Integration," 2015 Int. Conf. Adv. Comput. Commun. Informatics, pp. 1656-1660, 2015.

[3] K. Wagh and R. Thool, "A Comparative Study of SOAP Vs REST Web Services Provisioning Techniques for Mobile Host," J. Inf. Eng. Appl., vol. 2, no. 5, pp. 12-16, 2012.

[4] M. L. Pandini, Z. Arifin, and D. M. Khairina, "Design web service academic information system based multiplatform," 2014 1st Int. Conf. Inf. Technol. Comput. Electr. Eng. Green Technol. Its Appl. a Better Futur. ICITACEE 2014 - Proc., pp. 297-302, 2015.

[5] Z. Niu, C. Yang, and Y. Zhang, "A design of cross-terminal web system based on JSON and REST," Proc. IEEE Int. Conf. Softw. Eng. Serv. Sci. ICSESS, pp. 904-907, 2014.

[6] M. Arroqui, C. Mateos, C. Machado, and A. Zunino, "RESTful Web Services improve the efficiency of data transfer of a whole-farm simulator accessed by Android smartphones," Comput. Electron. Agric., vol. 87, pp. 14-18, 2012.

[7] M. H. Bohara, M. Mishra, and S. Chaudhary, "RESTful Web Service integration using Android platform," Fourth Int. Conf. Comput. Commun. Netw. Technol., pp. 1-6, 2013.

[8] R. Ramanathan and T. Korte, "Software service architecture to access weather data using RESTful web services," Fifth Int. Conf. Comput. Commun. Netw. Technol., pp. 1-8, 2014.

[9] E. R. Subhiyakto and D. W. Utomo, "RMTool; Sebuah Aplikasi Pemodelan Persyaratan Perangkat Lunak menggunakan UML,' JNTETI, vol. 6, no. 3, pp. 268-274, 2017.

[10] Y. P. Astuti et al., "Pengembangan Sistem Informasi Dengan Metode Waterfall Untuk Pengarsipan Data Wajib Pajak," vol. 16, no. 2, pp. 106-113, 2017.

[11] E. R.; Subhiyakto, Y. P. ; Astuti, L. ; Umaroh, D. W. Utomo, E. H. ; Rachmawanto, and C. A. Sari, "Rancang bangun sistem informasi pengarsipan data pasien klinik cemara," Techno.com, vol. 16, no. 1, pp. 25-34, 2017.

[12] E. R. Subhiyakto and N. Safina, "Rancang Bangun Sistem Informasi Inventaris BPJS Ketenagakerjaan Cabang Pekalongan," J. Sains dan Teknol., vol. 6, no. 1, pp. 72-81, 2017.

[13] E. Subhiyakto and M. Kamalrudin, "Customization of Requirements Modeling Tool For Software Engineering Education," Int. Symp. Res. Innov. Sustain., vol. 2014, no. October 2014, pp. 1581-1584, 2014.

[14] D. W. Utomo et al., "Tool Enhancement For Collaborative Software Engineering Education," vol. 2015, no. Sentika, pp. 9-16, 2015.

[15] A. Dennis, B. H. Wixom, and R. M. Roth, System Analysis and Design. 2012.

[16] E. R. Subhiyakto and D. W. Utomo, "Software Testing Techniques and Strategies Use in Novice Software Teams," J. Sist. Inf., 2016.

[17] E. R. Subhiyakto and D. W. Utomo, "Strategi, teknik, faktor pendukung dan penghambat pengujian untuk pengembang perangkat lunak pemula," in Seminar Nasional Teknologi Informasi dan Komunikasi 2016 (SENTIKA 2016), 2016, vol. 2016, no. Sentika, pp. 236-241. 